\title{
Social work and the practice of social justice: An initial overview
}

\author{
Michael O’Brien
}

Associate Professor Mike O'Brien works in the social policy and social work programme at Massey University, Albany campus. He has been at Massey University since 1980 and in 2009 was Astrid Lindgren Guest Professor at Växjö University, Sweden. He is a life member of the ANZASW and a former President, and is currently a member of the Association's Social Justice and Human Rights Governance Board. He is active in a range of social justice and social service groups and has written extensively on issues of child poverty, social security and social services.

\begin{abstract}
Social justice is a key element in social work. A sample of 192 ANZASW members recently completed a questionnaire describing their approach to social justice and the links between social justice and their practice. This overview article provides an initial summary of their thinking about and approach to social justice in that practice and reflects the various ways in which that practice is shaped by and reflects dimensions of social justice.
\end{abstract}

\section{Introduction}

Social work codes of ethics internationally (including the Aotearoa New Zealand Association of Social Workers (ANZASW) and International Federation of Social Workers (IFSW) Codes), social work literature and formal and informal discussions among social work practitioners give significant attention to social justice as the basis of social work practice. (See the special edition of the British Journal of Social Work, 2002; Ferguson, 2008; FigueiraMcDonough, 2007; Humphries, 2008; Sowers \& Rowe, 2007) as indicative examples of this.) While there is significant debate within the academic and professional literature about the definition of social justice (Craig, 2002; Lister, 2008; Piachaud, 2008; Wolff, 2008), in broad terms, the three components identified by Lister (2008), namely redistribution, recognition and respect, are all reflected with varying emphases in current debates. Craig's definition of social justice gathers the diverse elements together very effectively:

...a framework of political objectives, pursued through social, economic, environmental and political policies, based on an acceptance of difference and diversity, and informed by values concerned with: achieving fairness, and equality of outcomes and treatment; recognising the dignity and equal worth and encouraging the self-esteem of all; the meeting of basic needs; maximizing the reduction of inequalities in wealth, income and life chances; and the participation of all, including the most disadvantaged (Craig, 2002, pp. 671-672).

While debates and commentary have given considerable attention to the ways in which social work has (or, more commonly, has not) fulfilled its expressed commitment to social justice, little attention has been given to how the concept is used (or not) by practitioners in discussing their social work practice. Hawkins, Fook and Ryan (2001) constitute an interest- 
ing exception to this generalisation in their discussion of student and practitioner language in discussing case vignettes. The current article provides an overview of work undertaken recently with a sample of ANZASW members to ascertain their understanding of the idea of 'social justice', the influences on that definition, current social justice priorities and sought examples from their practice about the application and utilisation of the principles of social justice. One hundred and ninety one questionnaires were returned from the original sample; many of you who are reading this article will be among those participants. (Table one provides details of the sample.) Your contribution and that of your colleagues is warmly acknowledged and appreciated; the time and thought taken to answer the questions, and the nature of the examples, provide both testimony to your work and fascinating information about social work practice in Aotearoa New Zealand. This overview article is designed to identify key issues and themes which emerged and is aimed at providing some, albeit initial, feedback about those issues and themes, especially for the social workers who participated in the project, but also for the wider Association membership. Other, more detailed, publications are under preparation and will follow subsequently.

Table one. Characteristics of the sample.

\begin{tabular}{|c|c|c|c|}
\hline & ANZASW membership & Sample & Participants \\
\hline Questionnaires distributed & 3,914 & 710 & $191(27 \%)$ \\
\hline Social work qualification & Details not available & & $86.8 \%$ \\
\hline Ethnicity & $\begin{array}{c}\text { Māori } 20.3 \% \\
\text { Non-Māori } 52.2 \%\end{array}$ & $\begin{array}{c}\text { Māori } 27.5 \% \\
\text { Non-Māori } 72.5 \%\end{array}$ & $\begin{array}{l}25.9 \% \\
68.9 \%\end{array}$ \\
\hline Age distribution & $\begin{array}{cl}<30 & 7.79 \% \\
31-40 & 20.06 \% \\
41-50 & 30.07 \% \\
51-60 & 25.6 \% \\
>60 & 6.95 \%\end{array}$ & & $\begin{array}{l}6.8 \% \\
21.6 \% \\
22.6 \% \\
32.1 \% \\
13.7 \%\end{array}$ \\
\hline Gender & $\begin{array}{l}\text { Female } 82 \% \\
\text { Male } \quad 18 \%\end{array}$ & & $\begin{array}{ll}\text { Female } & 75.8 \% \\
\text { Male } & 21.1 \%\end{array}$ \\
\hline
\end{tabular}

\section{The information gathered}

The participants were asked to provide information on their current employment, their field of practice and the type of agency in which they are currently working, their length of time in social work practice, whether or not they had a recognised professional qualification or some other qualification and a range of demographic data in relation to age, gender and ethnicity. The questions focused on their social work practice by asking about their definition of social justice, the factors which had shaped their thinking about and approach to social justice and the current social justice priorities affecting practice. A group of questions also asked them to describe an incident from their practice involving issues of social justice and asked them to describe action taken to counter injustice or to promote social justice. Finally, the participants were asked to prioritise a range of ideas about social justice, using a 1-7 scale. (The list of ideas can be found in Appendix one.) There were 14 questions in total. 
The discussion below summarises the major issues which emerged from the responses to those questions.

\section{The practice of social justice}

As noted above, a number of commentators have argued recently that social work and social workers have either retreated from or abandoned the profession's historical commitment to social justice. (See Figueira-McDonough, 2007 for a discussion of some of this material.) In making those arguments, the critics have highlighted social work's increasing emphasis on professional status, the impact of some approaches to the politics of identity and to new social movements in moving social workers' focus away from issues of poverty and redistribution and the impact of managerialism, neo-liberalism and public choice on social work and social workers. (Ferguson, 2008 provides a useful discussion of some of these issues.) It is argued (in my view, with some justification) that the voice of social work and social work organisations in New Zealand and around the world has been weak and comparatively quiet on a wide range of social questions and social issues that are of considerable importance to individuals, families and communities with which social workers work. However, in those commentaries and critiques, there has been scant attention to how social workers approach their work, what they think about the nature of what they do and their analysis of what is happening in their practice.

In fact, the participants in this research project were clear that social justice ideas are very important in their daily practice, citing examples from a range of settings which demonstrated and illustrated how these ideas influence their analysis and their actions. While that action was primarily limited to their daily work (an issue to which I will return below), they were clear that social justice was an important part of their practice. This was reflected at a number of levels and in multiple ways. Most commonly, it was illustrated by examples which described actions taken in support of users, actions which reflected advocacy for, with and on behalf of those users and their families. At this level, the advocacy work aimed to secure changes that mattered to those users and their families by, for example, getting organisations to review decisions about access to services and/or supporting those users to take action against an individual or group where some injustice had occurred. Two examples from the participants provide good illustrations of this. One participant talked about how she 'supported a young offender to take a complaint (successfully) against a police officer who broke his jaw', while another gave the example of 'advocating for clients at Work and Income, Housing New Zealand, city council and members of Parliament when they are being denied resources'.

Examples were not limited to individual users and their families, with some of the practitioners describing actions they had taken to bring about changes in practices and policies at an organisational level, changes which would not be limited to the current user, but would have a wider impact on other subsequent users. While there were less examples in this group, the examples which were provided were significant and interesting. One of the social workers described what she had done to change procedures when a user was unable to secure a food parcel, while another talked about actions taken in relation to a child from an African community who had been removed from parental care. Another social worker talked about how her team 'tried to remove the term 'social admission' from the hospital. It is a demeaning tag often applied to elderly patients which affects the way staff work with them and treatment efforts provided'. 
Informed by their social justice framework, a smaller group of participants provided examples of actions they had taken to effect changes at the broader policy and political level, the level at which, as I noted above, much of the criticism about social work and social workers' lack of attention to social justice has occurred. The number of participants who provided examples of this kind was quite small, lending some weight to the more general argument that social workers have, to a significant extent, given little attention to this part of their practice; I will return to this issue in the conclusion of this article. Those who provided examples described gathering statistical data from their practice and using that data to argue for changes, while another talked about action she had taken arising from her work with adults with hearing loss, working with other agencies, lobbying Ministers and others to change policies that meant hearing aids were not funded for her client because of the client's age. Government policy was subsequently changed. A small number described taking actions at this broader level and being subject to disciplinary action as a result, for example, of joining a march against social security benefit cuts.

\section{Defining social justice}

In setting out their definitions of social justice, the practitioners highlighted two important dimensions, namely fairness and equality, dimensions which are well articulated in the extensive international literature on the subject. (See the references above.) In their discussions of these dimensions, equality was talked about more frequently than fairness, with a number of practitioners linking the two together: 'Social justice is the unifying term given to the pursuit of equality and fairness in all human situations and in relation to the use and distribution of resources'. 'Equality' has, of course, many levels of meaning and these were reflected in the ways in which the practitioners defined the terms and described what they meant. Some used 'equality' to refer to equal opportunities, arguing that these opportunities should ensure that everybody has 'the ability to participate in everyday life'. Others took a stronger view, with a more structural approach to issues of equal opportunities, arguing, for example, that equal opportunities requires that 'factors such as ethnicity, gender, income, culture, geographical location are taken into account in a way that still allows equal opportunity'.

Others were more explicit that equality requires equity and a more active approach to the pursuit of equality than relying on what might be described as a 'liberal' approach to equal opportunity. For one of the participants, for example, social justice requires 'redistributing resources and power in society to overcome disadvantage. It's about equity rather than just equal distribution'. Equality (and social justice) would, it was argued, be achieved through some form of redistribution (a word that was used by four of the participants), not through relying simply on equal opportunities to achieve social justice.

For some, equality and access were closely linked, most commonly with 'access' being crucial to obtaining what is needed to achieve equal outcomes, not just equal opportunities. One of the participants captured this well when she defined justice as being about access, going on to note that this is not a simple equality, because 'striving for equality does not always result in things being equal'. In a similar vein, a number of the participants defined access as a core component of 'fairness', the second dominant definitional dimension. Here, too, access was described and understood not simply as an entry point to services, but, more commonly as having broader characteristics: 'if there was social justice, there would be equity of access that didn't rely on influences such as wealth, power, gender, culture'. 
'Fair treatment' was the commonest use of the idea of 'fairness, both in the sense that services should not discriminate at an individual level and in the sense that 'fair treatment' also requires that 'everyone no matter what their socioeconomic circumstances can be sure of fair and just treatment by the authorities'. Significantly, this social worker went on to say that this 'includes redress for past wrongs and speedy resolution of present injustices'. Two participants referred to the Treaty of Waitangi and the rights of indigenous peoples as part of their approach to fairness and social justice, but without linking these explicitly with issues of redress. Similarly, reflecting the emphasis on recognition which has developed as an integral aspect of social justice in recent times (see Lister, 2008 for a discussion of this), a small number of participants explicitly referred to cultural diversity and difference as integral parts of their thinking about the nature of fairness, while others talked more generally about issues of discrimination.

In addition to these broader discussions, a number of other participants referred to social justice in more specific terms. On occasions, they used terms such as 'access', 'opportunity' and 'discrimination' as integral to their thinking about social justice, but without actively associating these words with either equality or fairness. They may have made that link for themselves, but did not articulate that in their written statements.

Two other specific terms require brief comment. A number of the social workers talked about advocacy as a fundamental part of their definition of social justice. Advocacy for some was focused at the level of their practice with individual users, while for others, the purpose of advocacy was to press for more substantive and structural social change, with one of the participants neatly linking these two uses together in describing social justice as 'a commitment to both enabling users to find solutions to their problems and changing the structures of society'.

The other definitional term that warrants brief mention is respect, a word which Lister (2008) uses in her recent discussion about social justice and poverty. Its use is significant, not because it is a term which was widely used, but because it captures some of the recent debates in the academic and professional literature. Respect, said one of the participants, means 'a society where resources are shared according to need, all people are respected and everyone has the common rights of citizenship no matter'.

\section{Shaping thinking about social justice}

This, then, represents a very brief overview of social justice in practice and the approaches used by these practitioners to define what they mean by the term 'social justice'. What influenced and shaped their thinking about social justice? In brief, responses to this question fell into three broad areas. First, there were some participants who highlighted their own family histories, personal experiences and/or religious beliefs as being significant. Among this group, participants referred to the importance of their family's involvement in social work and related activities. For some of the participants, their upbringing and lives as Māori and their experiences of colonisation and indigenous development were what shaped their approach to social justice. Others referred to their personal experiences of being a sole parent, of being lesbian and experiences of abuse as the most significant factors. Reflecting both their historical experiences and current lives, a number of participants referred to Christianity, religious faith and exposure to particular theological traditions such as liberation theology as the genesis of their social justice thinking. 
A second group focused on their tertiary education experiences, including their social work education, as having the most influence on their thinking. These practitioners referred to both specific thinkers whom they had an opportunity to read and discuss and their professional educational experiences as the most important influences. A third group, the largest of the three, described how a range of experiences in working in the social services had influenced their thinking, especially their reflection on the circumstances and lives of users. For some, it was simply their 'experiences' which were the most significant, while others were much more specific, noting, for example, the impact of 'the struggles of clients', 'the impact of poverty on children' and 'experiences of racism and prejudice for migrant people' as being important influences. Alongside these three broad groupings, some of the participants referred to generalised values such as 'fairness' and 'equal opportunity' or to more specific illustrations such as 'equity for indigenous groups', without indicating what had in fact shaped and created these particular value positions, for such values don't simply drop out of the sky but are shaped by a range of experiences.

\section{Social justice, redistribution and recognition}

As I noted briefly at the beginning of this overview, the social justice literature in the last two decades has drawn out redistribution and recognition as central dimensions of social justice. The relationship between the two has been the subject of considerable debate and discussion (see references in the introduction above). It is not appropriate or possible to explore that debate here, but it is of interest to reflect on the ways in which those two dimensions are reflected in the responses of these participants. Questions on social justice priorities in practice and the ranking of the seven different ideas about social justice provide some initial indications about how the practitioners approach the two dimensions. (Appendix one sets out the list of seven items used in the ranking.)

When asked to identify the three most important social justice priorities facing social work practice, issues of poverty, inequality and income adequacy formed the largest single category of responses. (Participants were not asked to rank these priorities.) Some of the participants talked quite specifically about the need for income redistribution and 'the gap between rich and poor' as the most significant. One in six of the participants identified income inequality in some form as a priority area, while a similar number identified poverty (expressed in various ways) as one of their current priorities. Turning briefly to the recognition dimension, 11 participants identified the status of tangata whenua, Māori social and political aspirations and more general issues related to Māori and Māori development as among their social justice priorities. Six identified general considerations around cultural appropriateness and responsiveness, while for others, the priorities revolved specifically around questions of discrimination and prejudice, particularly, but not exclusively, in relation to issues of racism and ethnicity. A small number of participants saw the priority in this area as being 'treating all groups the same'; for them 'discrimination' arose from what they saw as the 'advantaged' treatment accorded to some groups.

Moving to the ranking of ideas about social justice, Table two sets out an initial summary of the responses reflecting the most important, least important and the middle point between the extremes. While acknowledging the limitations and difficulties with the approach used, it is significant that those items which focused around what might loosely be called the 'redistribution' dimension received a much stronger number of highest priority ranking (scores 
of 1 or $1=$ ) than those which, equally loosely, attempt to reflect the recognition dimension of social justice. (Figures are raw numbers rather than percentages).

Table two. Selected ranking of ideas about social justice.

\begin{tabular}{lcccc}
\hline & $\mathbf{1}$ & $\mathbf{1}=$ & $\mathbf{4}$ & $\mathbf{7}$ \\
Opportunity & 38 & 26 & 12 & 14 \\
Diverse treatment & 22 & 23 & 19 & 21 \\
Fair distribution & 22 & 23 & 17 & 8 \\
Law treatment & 25 & 28 & 21 & 28 \\
Indigenous equity & 9 & 23 & 21 & 17 \\
Cultural equity & 4 & 24 & 17 & 23 \\
Extra resources & 18 & 19 & 22 & 23 \\
& & & & \\
\hline
\end{tabular}

(Note: Some participants gave items an equal ranking and this is reflected in the differences between the aggregate number of responses receiving the highest priority and those given the lowest priority)

While mindful of the limitations associated with this data, two brief comments are warranted. First, issues of income adequacy and poverty are still significant in the social workers' thinking about social justice. Both their own spontaneous listing of priorities and their ranking of ideas reflect this. This suggests that professional associations and other appropriate bodies can confidently be proactive around these issues, knowing that in doing so, they reflect the views from practice. Second, both redistribution and recognition are important, items associated with the former being given more weight and significance than the latter, but certainly not in a way that would suggest that social workers and social work organisations and representatives can focus on one rather than the other. As much of the literature attempts to do, both dimensions are important.

\section{Conclusion}

In describing these actions (and there are many other examples which could be used), the social workers were actively using the language and concepts of social justice to describe their work, their approach to their particular social work tasks and what they were trying to achieve though that work. The discussion was replete with words such as 'advocacy' , 'access', 'fairness', 'fair treatment' and 'equal treatment', all reflected in Craig's definition of social justice above. They were words which were used in the context of discussing their practice activities. While that discussion occurred much more in the context of individual examples than in broader social policy considerations, it is significant that it was language which was used to talk about their practice and their experiences in that practice. The significance lies simply in the extensive use of social justice language to describe that daily practice. Framing their work in this way suggests a need to reconsider some of the discussions about the relationship between social justice and social work. Certainly, the discussion from these practitioners is primarily, almost entirely, about individual actions aimed at more socially just outcomes and experiences for users. The discussion and description is only occasionally aimed at the broad structural levels around issues of redistribution and recognition and respect; it is the failure to act and be active at this level that has led to the criticism of social work and social workers. Nonetheless, it retains and expresses a clear social justice orientation among the practitioners; discussions about social justice and social work need 
to extend to exploring this element in practice. The key task for practitioners and for those with wider professional responsibilities is to take these individual examples and illustrations and provide the skills, support and resources to ensure that the practitioners' work is converted and translated into active participation in the broader structural dimensions of redistribution, recognition and respect.

\section{Appendix one: Ideas about social justice}

How would you rank the following ideas about justice:

( 1 = most important, 7 = least important)

Creating equal opportunity

Ensuring diverse treatment to meet individual circumstances

Ensuring fair distribution of resources

Ensuring the rules/law treats everybody the same

Equity for indigenous groups

Equity for all cultural groups

Providing extra resources to overcome economic disadvantage

\section{References}

Craig, G. (2002). Poverty, social work and social justice. British Journal of Social Work, 32(6), 669-682.

Ferguson, I. (2008). Reclaiming social work. Challenging neo-liberalism and promoting social justice. London: Sage.

Figueira-McDonough, J. (2007). The welfare state and social work. Pursuing social justice. London: Sage.

Hawkins, L., Fook, J., \& Ryan, M. (2001). Social worker's use of the language of social justice. British Journal of Social Work, 31(1), 1-13.

Humphries, B. (2008). Social work for social justice. Basingstoke: Palgrave Macmillan.

Ife, J. (2001). Human rights and social work. Cambridge: Cambridge University Press.

Jordan, B. (2004). Emancipatory social work? Opportunity or oxymoron. British Journal of Social Work, 34(1), 5-19.

Lister, R. (2008). Recognition and voice: The challenge for social justice. In G. Craig, T. Burchardt \& D. Gordon (Eds.). Social justice and public policy. Seeking fairness in diverse societies. Bristol: The Policy Press.

Piachaud, D. (2008). Social justice and public policy: A social policy perspective. In G. Craig, T. Burchardt \& D. Gordon (Eds.). Social justice and public policy. Seeking fairness in diverse societies. Bristol: The Policy Press.

Sowers, K. \& Rowe, W. (2007). Social work practice and social justice. From local to global perspectives. Canada: Thomson.

Wolff, J. (2008). Social justice and public policy: A view from political philosophy. In G. Craig, T. Burchardt \& D. Gordon (Eds.). Social justice and public policy. Seeking fairness in diverse societies. Bristol: The Policy Press. 